\title{
Empirical investigation of the VaR of hedge funds using daily data
}

\author{
Florent Pochon*, and Jérôme Teïletche \\ *IXIS Corporate Investment Bank, 47 Quai d'Austerlitz, 75648, Paris Cedex 13, France. \\ Tel: + 331585514 69; E-mail: fpochon@ixis-cib.com
}

Received (in revised form): 11th September, 2006

Florent Pochon is a quantitative economist at IXIS Corporate Investment Bank, Paris, France.

Jérôme Teïletche is Professor of Finance at the Université Montesquieu Bordeaux IV, Bordeaux, France. At the time of writing this study, he was a quantitative economist at IXIS Corporate Investment Bank, Paris, France.

\section{Practical applications}

On top of operational risk, market risk is substantial for hedge fund investors. As hedge fund returns exhibit highly non-Gaussian features, the issue of choosing a good model to compute and forecast VaR for hedge funds is crucial. This has become all the more important as hedge funds now deliver weekly or daily NAV estimates as compared to monthly or quarterly ones', a few years ago. This paper uses a high-frequency dataset for a CTA index. We show that the efficiency of one-day-ahead VaR primarily depends on the type of quantiles used for computing VaR forecasts, not on the variance forecasting model. More precisely, among popular models, the use of Cornish-Fisher expansion appears to be the most performing method to compute adequate quantiles.

\begin{abstract}
We compare the performance of several Value-at-Risk (VaR) models when applied to a high-frequency hedge fund index. Our analysis is carried out on the Barclay/Calyon CTA daily index available since early 2000. We use 1-day-ahead VaR forecasts for various thresholds (10, 5 and 1 per cent) and apply univariate and multivariate VaR backtesting procedures. Our results show that the efficiency of VaR forecasts primarily depends on the type of quantiles used for computing VaR forecasts. The choice of the model used to forecast volatility (simple smoothing average, EWMA, symmetric or asymmetric GARCH models) proves much less important in that specific case. Our results also show that the most flexible form is the
\end{abstract}

Cornish-Fisher expansion for 10 and 5 per cent thresholds, whereas Student quantiles are the best to forecast efficiently 1 per cent VaRs. Derivatives Use, Trading \& Regulation (2007) 12, 314-329. doi:10.1057/palgrave.dutr.1850051

Keywords: VaR; hedge funds; CTA index; market risk

\section{INTRODUCTION}

While alternative management is acknowledged for its surprisingly high and recurrent returns, it has also been associated with less favourable episodes, such as the dramatic bankruptcy of star fund LTCM. Alternative management investors
Derivatives Use, Trading \& Regulation Vol. 12 No. 4, 2007 pp. 314-329 (C) 2007 Palgrave Macmillan Ltd 1357-0927 \$30.00 
have to contend with numerous risk factors like liquidity risk, operational risk and credit risk. For these risks are perhaps even more substantial in alternative management than in conventional management, because of its unique legal status since, they are often offshore companies subject to less restrictive regulations requiring high entry tickets and restrictive exit conditions, and because of their utilisation of sophisticated instruments with a major leverage effect.

Market risk is also found in the strategies of hedge funds. This is all the more the case for directional strategies that lead to unhedged positions based on an expectation of how the market as a whole is going to move. We will focus this study on market risk and primarily on the canonical measure of market risk, Value-at-Risk (VaR) that is defined as the maximum loss that one can expect to incur according to a certain degree of confidence over a given horizon.

Despite all the afore-mentioned interest in hedge funds, their VaR for the time being has led to few analyses, notably in comparison with other asset classes. Lhabitant ${ }^{1}$ proposes a multifactorial approach à la Sharpe, ${ }^{2,3}$ where the sensitivity of each hedge fund is estimated according to indices of the various strategies. In other words, the VaR of individual hedge funds is explained according to that of strategies, and this curbs the model's predictive capacities. Pochon and Teiletche ${ }^{4,5}$ condition the returns of the various strategies of hedge funds on the returns of standard assets, in this case the S\&P and the $\mathrm{Baa} / \mathrm{Aaa}$ spread, enabling nonlinear relationships to be used via a mixture of Gaussian distributions. Faced with the non-normality of the returns of hedge funds, Signer and Favre ${ }^{6}$ propose drawing on the Cornish-Fisher expansion to calculate VaR as Zangari ${ }^{7}$ had proposed for standard assets. Bacmann and
Gawron, ${ }^{8}$ Bali and Gockan ${ }^{9}$ confirm the superiority of this approach, as well as the one based on the Extreme Value Theory over the more conventional approaches located within the Gaussian framework. All these previous approaches are primarily backward looking, that is, $\mathrm{VaR}$ is estimated from the distribution of past variations in prices (albeit varying over time). In practice, risk management in large institutions is often based on forward-looking approaches, that is, they seek to predict VaR. To do so, GARCH temporal series models or constrained versions of such models (EWMA model of RiskMetrics) are frequently used. Monteiro ${ }^{10}$ compares various GARCH models and various specifications of conditional distribution. He shows that an estimation of simple (unconditional) variance combined with a Cornish-Fisher approach offers the best results.

A common limitation to all these studies is the fact that they are based solely on monthly frequency data. This is linked to the fact that hedge funds for a long time simply published monthly track records. For various reasons, notably the larger presence of institutional investors, the development of fund platforms, the increasing professionalism and improvement in risk management within funds, etc, increasingly publish track records with a higher frequency, whether daily or weekly, notably when they invest in liquid vehicles. The main contribution of this research is that it is, to the best of our knowledge, the first to draw on this type of data to analyse the $\mathrm{VaR}$ of hedge funds. More precisely, we use the Barclay/Calyon index covering the performances of a set of CTA funds. This leads to a more sophisticated understanding of the market risk hedge funds are exposed to and enhanced adequacy of academic research on the other assets that is just about systematically based on daily data. Looking 
forward, this enables us to implement more complete back-testing than in previous studies.

We show that efficient 1-day-ahead VaR forecasts are achievable. In our case, the results primarily relies on the type of quantiles used for VaR computations, with the Cornish-Fisher quantiles being the most flexible ones for 10 and 5 per cent VaRs, and the Student's the most suitable for 1 per cent VaR. Interestingly, the choice of the models used to forecast volatility proves much less important. After presenting our methodology in the next section, we give detailed results in the penultimate section and draw a conclusion in the final section.

\section{METHODOLOGY}

\section{General principle}

Generally speaking, the VaR of an investment represents the maximum loss that can be considered, given a certain degree of confidence at a given horizon. More formally, if we denote by $1-\alpha$ the degree of confidence and $r_{t}$ the return linked to the investment as recorded at date $t, \mathrm{VaR}$ is defined by the following relationship:

$$
\operatorname{Pr}\left[r_{t}<\operatorname{VaR}_{t \mid t-1}(\alpha)\right]=\alpha
$$

Note that $\mathrm{VaR}$ is defined here in an ex ante manner, that is, the $\mathrm{VaR}$ expected in period $t$ conditional on the information available in period $t-1$. For we are trying here to test which models enable an efficient $\mathrm{VaR}$ to be constructed with respect to a track record $t=1, \ldots, T$. More precisely, we introduce the indicative function associated with violations of VaR:

$$
I_{t}(\alpha)= \begin{cases}1 & \text { if } r_{t}<\operatorname{VaR}_{t \mid t-1}(\alpha) \\ 0 & \text { otherwise }\end{cases}
$$

It is accepted that the problem of the validity of the VaR model is then summarised by the verification of two hypotheses (Christoffersen, ${ }^{11}$ Campbell $^{12}$ ):

\section{Unconditional coverage}

The probability that an ex post loss exceeds VaR forecasts must be exactly equal to $\alpha$, that is, $\operatorname{Pr}\left[I_{t}(\alpha)=1\right]=E\left[I_{t}(\alpha)\right]=\alpha$.

\section{Independence}

Violations of $\mathrm{VaR}$ at various periods must be independent over time. In particular, $I(\alpha)$ has to be independent from past returns and past values of $\mathrm{VaR}$.

Berkowitz et al. ${ }^{13}$ show that these two hypotheses can be regrouped in a single hypothesis, so-called conditional coverage. It is expressed in statistical terms as the fact that demeaned violations of the $\mathrm{VaR}$ threshold represent a martingale difference:

$$
E\left[I_{t}(\alpha)-\alpha \mid \Omega_{t-1}\right]=0
$$

where the information set $\Omega_{t-1}$ includes past values of violations of $\mathrm{VaR}, I_{t-1}(\alpha), I_{t-2}(\alpha) \ldots$, but also any other variables known in period $t-1$, such as the levels of VaR or past returns.

Several tests of the conditional coverage hypothesis have been proposed in the literature. Christoffersen ${ }^{11}$ starts off from the transition matrix of violations of $\mathrm{VaR}$,

$$
\Pi=\left(\begin{array}{ll}
1-\pi_{01} & \pi_{01} \\
1-\pi_{11} & \pi_{11}
\end{array}\right)
$$

where $\pi_{i j}=\operatorname{Pr}\left[I_{t}(\alpha)=j \mid I_{t-1}(\alpha)=i\right]$. He shows that under the hypothesis of nil conditional efficiency of $\mathrm{VaR}$, the two linear restrictions $\pi_{01}=\pi_{11}=\alpha$ must be verified, and this can be 
tested via a likelihood ratio:

$$
\begin{aligned}
L R_{C C}= & -2 \log \left[L\left(\Pi_{2} ; I_{1}(\alpha), \ldots, I_{T}(\alpha)\right)\right. \\
& \left.-L\left(\Pi_{1} ; I_{1}(\alpha), \ldots, I_{T}(\alpha)\right)\right] \sim \chi^{2}
\end{aligned}
$$

with

$$
\begin{aligned}
& L\left(\Pi_{1} ; I_{1}(\alpha), \ldots, I_{T}(\alpha)\right) \\
& =\left(1-\pi_{01}\right)^{n_{00}} \pi_{01}^{n_{01}}\left(1-\pi_{11}\right)^{n_{10}} \pi_{11}^{n_{11}}
\end{aligned}
$$

for $n_{i j}$ the number of cases where $I_{t}(\alpha)=j$

for $I_{t-1}(\alpha)=i$ and $L\left(\Pi_{2} ; I_{1}(\alpha), \ldots\right.$,

$\left.I_{T}(\alpha)\right)=\left(1-\pi_{2}\right)^{\left(n_{00}+n_{10}\right)} \pi_{2}^{\left(n_{01}+n_{11}\right)}$ with

$\pi_{2}=\left(n_{01}+n_{11}\right) /\left(n_{00}+n_{10}+n_{01}+n_{11}\right)$. The

Christoffersen test is thus as a joint test of a correct unconditional coverage noted $L_{U C}$, where under the null $I_{\mathrm{t}} \sim$ i.i.d Bernouilli $(\alpha)$, and a test of independence denoted $L_{I N D}$, where under the null $\pi_{01}=\pi_{11}, L R_{C C}=L R_{U C}+L R_{I N D}$ where $L R_{U C}$ and $L R_{I N D} \sim \chi^{2}$. The Christoffersen test $L R_{C C}$ presents however the drawback of dealing only with first-order dependencies - and is therefore not very general - as well as a second drawback of not allowing dependency with other variables such as returns.

The Engle and Manganelli test, ${ }^{14}$ the so-called CaViar test, solves this problem simply by proposing a regression of demeaned violations, so-called Hits with $\mathrm{Hit}_{t}(\alpha)=I_{t}(\alpha)-\alpha$, on their past values and any other variable:

$$
\begin{aligned}
\operatorname{Hit}_{t}(\alpha)= & \lambda+\sum_{k=1}^{K} \beta_{k} \mathrm{Hit}_{t-k}(\alpha) \\
& +\sum_{k=1}^{L} \gamma_{k} g\left[\mathrm{Hit}_{t-k}(\alpha),\right. \\
& \left.\operatorname{Hit}_{t-k-1}(\alpha), \ldots, r_{t-k}, \ldots\right]+\varepsilon_{t}
\end{aligned}
$$

$g[$.$] stands for any function. The conditional$ coverage hypothesis is then simply tested via Student or Fisher tests of the nullity of regression coefficients including the constant. We use the Wald statistics in association with the test of conditional efficiency hypothesis, we note $E M_{C C}$ :

$$
E M_{C C}=\frac{\hat{\psi} Z^{\prime} Z \hat{\psi}^{\prime}}{\alpha(1-\alpha)} \sim \chi^{2}(K+L+1),
$$

with $\psi=\left(\lambda, \beta_{1}, \ldots, \beta_{k}, \gamma_{1}, \ldots, \gamma_{l}\right)^{\prime}$ and $Z$ the matrix of the corresponding explanatory variables. In our application, we set $K=5$ and $g\left[\operatorname{Hit}_{t-k}(\alpha), \operatorname{Hit}_{t-k-1}(\alpha), \ldots, r_{t-k}, \ldots\right]=V a R_{t \mid t-1}$ (ie the ex ante $\mathrm{VaR}$ ).

Lastly, Berkowitz et al., ${ }^{13}$ propose carrying out simple tests of the absence of autocorrelation in the time series of Hit $t_{t}$ 's via a standard Ljung-Box test for which the statistic is given by $L B(K)=$ $T(T+2) \sum_{k=1}^{K} \rho_{k}^{2} /(T-k) \sim \chi^{2}(K)$ and they recommend having $K=5$. Hurlin and Tokpavi ${ }^{15}$ propose widening the test to a multivariate case, that is the various levels of coverage $\alpha$, via the statistic of the Li and McLeod test ${ }^{16}$

$$
\begin{aligned}
Q_{m}(K)= & T \sum_{k=1}^{K}\left(\operatorname{vec} R_{k}\right) \prime\left(R_{0}^{-1} \otimes R_{0}^{-1}\right) \\
& \times\left(\operatorname{vec} R_{k}\right) \sim \chi^{2}\left(K m^{2}\right)
\end{aligned}
$$

where $m$ stands for the different levels of coverage. The authors recommend drawing on $m=3$ for $\alpha=\{1$ per cent, 5 per cent, 10 per cent $\}$. We denote this test HT in the Tables below.

\section{Construction of volatility forecast: GARCH models and distributional hypotheses}

In compliance with academic and professional practice, all the VAR forecasting models we use in this study are based on the following formula:

$$
\operatorname{VaR}_{t \mid t-1}(\alpha)=z_{t \mid t-1}(\alpha) \times h_{t}
$$

The VaR forecast in $t-1$ at horizon $t$ is thus calculated as the product of the volatility forecast in $t-1$ at horizon $t$, denoted $h_{t}$, with a scalar that 
depends on the level of confidence, that is the $\alpha$-quantile denoted $z_{t \mid t-1}(\alpha)$.

With respect to volatility, we have chosen three types of models:

(i) Estimators based on simple sample standard deviation estimated on the latest $n$ returns:

$$
h_{t}=n^{-1} \sum_{\tau=1}^{n} r_{t-\tau}^{2}
$$

In practice, we use three alternative windows: 22 days $(n=22$, denoted SMA22), 66 days $(n=66$, denoted SMA66) and 250 days $(n=250$, SMA250).

(ii) Estimators based on GARCH models estimated over the last 250 trading days. In practice, we have drawn on five types of models that are presented in detail in the Table 1 (more details about the estimated models are available from the authors on request). These models stand out because of their specification, with notably a distinction between asymmetric models and symmetric models.

(iii) Estimators of an EWMA moving average type: $h_{t}^{2}=\lambda h_{t-1}^{2}+(1-\lambda) r_{t-1}^{2}$. In compliance with recommendations made by RiskMetrics, we pick $\lambda=0.94$. Note that the EWMA model has common characteristics with conventional estimators, since the latter is a specific case of EWMA where all the observations are equally weighted $(\lambda=1 / n)$ and with the GARCH estimators, since the EWMA model is obtained as a GARCH with nil long-term variance $(\omega=0)$ and integrated $(\alpha+\beta=1)$.

Note that in the calculation of $\mathrm{VaR}$ and the estimation of volatilities; whether in historical models or GARCH models, we omit the impact of the short-term average of returns. However, it is well known that the addition of the average, which is unstable over time and nearly nil on average in the long term, leads to adding noise, and this lowers the efficiency of volatility estimators (Canina and Figlewski ${ }^{17}$, Jorion ${ }^{18}$ ).

For the quantile $z_{t \mid t-1}(\alpha)$, we have chosen three measures:

- Quantiles resulting from the normal standard distribution.

- Quantiles stemming from a Student distribution. Student distribution, which includes normal distribution as a specific case for an infinite number of degrees of freedom,

Table 1: Univariate GARCH models

\begin{tabular}{lll}
\hline Model & $\begin{array}{l}\text { (A)Symmetric response } \\
\text { depending on returns sign }\end{array}$ & Specification \\
\hline GARCH & Symmetric & $h_{t}=\omega+\alpha r_{t-1}^{2}+\beta h_{t-1}$ \\
AV-GARCH - Absolute value & Symmetric & $h_{t}^{1 / 2}=\omega+\alpha\left|r_{t-1}\right|+\beta h_{t-1}^{1 / 2}$ \\
NARCH - Nonlinear GARCH & Symmetric & $h_{t}^{\lambda / 2}=\omega+\alpha\left|r_{t-1}\right|^{\lambda}+\beta h_{t-1}^{\lambda / 2}$ \\
EGARCH - Exponential GARCH & Asymmetric if $\gamma \neq 0$ & $\log \left(h_{t}\right)=\omega+\alpha \frac{\left|r_{t-1}\right|}{h_{t}}+\gamma \frac{r_{t-1}}{h_{t}}+\beta \log \left(h_{t-1}\right)$ \\
GJR-GARCH & Asymmetric if $\gamma \neq 0$ & $h_{t}=\omega+\alpha r_{t-1}^{2}+\gamma I_{\left[r_{t-1}<0\right]} r_{t-1}^{2}+\beta h_{t-1}$ \\
\hline
\end{tabular}


makes it possible to take into account the non-normality of the series. In particular, the distribution associated with Student distribution can be compatible with the phenomenon of excess kurtosis, as witnessed in daily returns of CTAs (cf below), once the number of degrees of freedom is reduced.

It partly explains the non-normality of the series, but distribution remains symmetric (asymmetric versions of Student distribution do exist, however; cf Hansen ${ }^{19}$ ). When we estimate the parameters of Student distribution throughout the period for the various GARCHs models, we find an average degree of freedom equal to 8.43 (ranging from 7.37 to 9.10). This is why we draw on a Student distribution with eight degrees of freedom for the calculation of the quantile.

- So-called Cornish-Fisher quantiles, which are based on an expansion around the normal distribution in order to take into account the asymmetry and the fat tails of the distribution. Formally, the quantile associated with the Cornish-Fisher expansion is given by:

$$
\begin{aligned}
z_{C F}(\alpha)= & z_{\text {normal }}(\alpha)+\frac{1}{6}\left(z_{\text {normal }}(\alpha)^{2}-1\right) S K \\
& +\frac{1}{24}\left(z_{\text {normal }}(\alpha)^{3}-3 z_{\text {normal }}(\alpha)\right)(K U-3) \\
& -\frac{1}{36}\left(2 z_{\text {normal }}(\alpha)^{3}-5 z_{\text {normal }}(\alpha)\right) S K^{2}
\end{aligned}
$$

with $z_{\text {normal }}(\alpha)$ the quantile of the normal distribution, $S K$ the skewness coefficient and $K U$ the kurtosis coefficient. In the above estimates, we use the values of these two parameters found over the whole of the period.

Finally, the quantiles used for the various thresholds and the various methods are
Table 2: Quantiles

\begin{tabular}{llll}
\hline $\begin{array}{l}\text { VaR } \\
\text { thresholds }\end{array}$ & Gaussian & $\begin{array}{l}\text { Student } \\
\text { (8 degrees } \\
\text { of freedom) }\end{array}$ & $\begin{array}{l}\text { Cornish-Fisher } \\
\text { Expansion }\end{array}$ \\
\hline $1 \%$ & -2.33 & -2.90 & -2.99 \\
$5 \%$ & -1.64 & -1.86 & -1.67 \\
$10 \%$ & -1.28 & -1.40 & -1.16 \\
\hline
\end{tabular}

summarised in the Table 2 (values rounded off to simplify their presentation).

\section{RESULTS}

\section{Data}

Our analysis is based on the Calyon Financial Barclay index, which is an equiweighted index, covering the returns of a set of large CTA funds that are open to new investments. In July 2006, the index was made up by 14 funds, while 17 belonged to it when the index was launched in January 2000. The list is reviewed at the beginning of each year. The index is not investable. The index and associated log-returns are represented in Figure 1. The sample ranges from January 2000 to June 2006 offering 1,693 daily returns. Table 3 shows descriptive statistics of these returns.

With a standard deviation of 0.58 per cent per day, the volatility of the index is close to 9 per cent per year. This is a high figure for an overall index of hedge funds, but typical for a CTA index. Even though the average return and the median return are very similar, distribution is significantly asymmetric in the direction of negative returns. It also presents kurtosis significantly above 3 so that the overall 


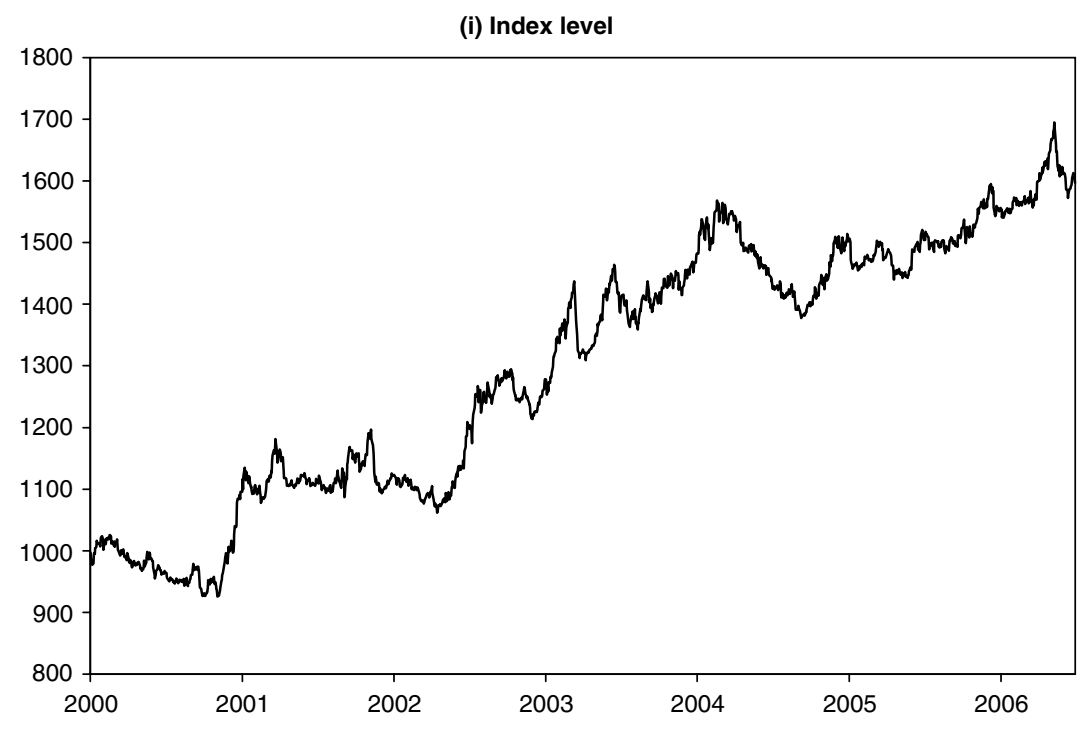

(ii) Daily log-return

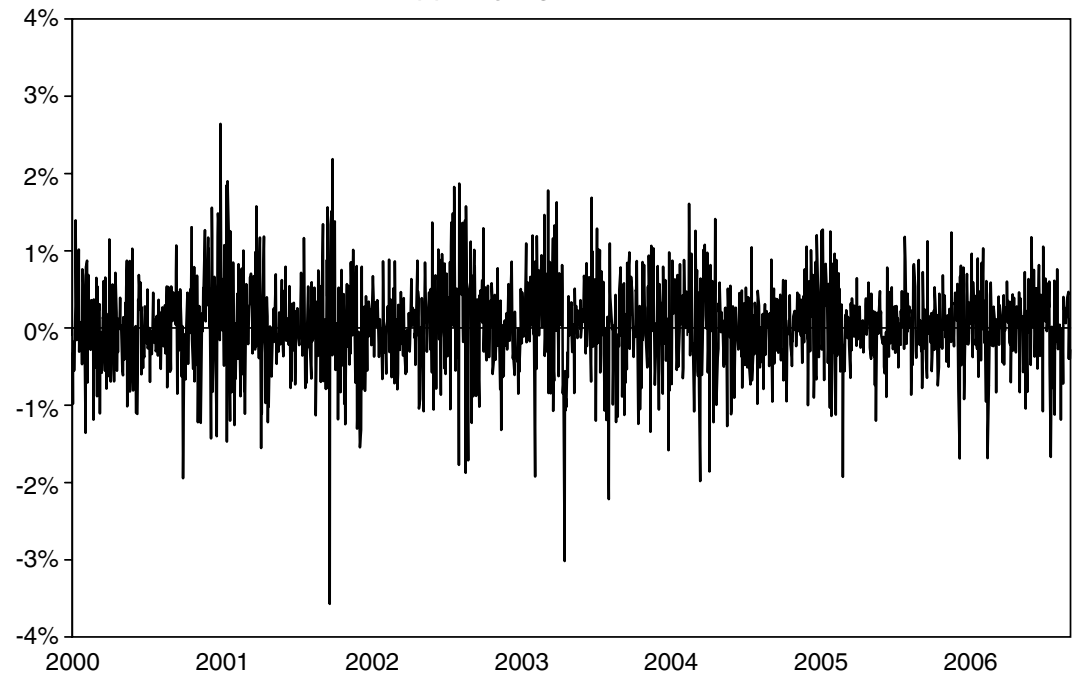

Figure 1: Calyon Financial Barclay CTA Index.

Source: http://www.calyonfinancial.com/tools/barclay.html

distribution is significantly different from a normal distribution. Such non-normality of unconditional distribution of returns might be linked to the presence of ARCH effects but could also combine with non-normality of conditional distribution. This is why we consider various distributional hypotheses, including some that are typical of fat tail or asymmetric distribution, and in particular, a Student distribution and a Cornish-Fisher expansion (see above). For their part, Ljung-Box statistics show that the series of returns does not display any dependence on average but high dependence on variance. This finding, 
combined with an ARCH-LM test, provides a justification for using GARCH models without an ARMA-like component.

\section{Out-of-sample VaR comparisons}

Results are reported in Tables 4-6, with univariate tests in panel As and the HT multivariate test in panel Bs. All the tests were computed on 1-day-ahead VaR forecasts. For every VaR threshold (10, 5 and 1 per cent), we compare the ability of various models to forecast volatility and $\mathrm{VaR}$ (historical smoothing averages, EWMA and GARCH models). Given the GARCH models are estimated on 250-day rolling windows, we are left with 1,442 out-ofsample forecasts.

We report the asymptotic $p$-values of the test statistics. Berkowitz et al. ${ }^{13}$ show that for small sample sizes and for 1 per cent VaR, the asymptotic critical values can be significantly misleading and thus use Dufour ${ }^{20}$ Monte Carlo technique to compute correct $p$-values. However, complementary analyses (not reported) showed us that the sample bias was not significant, given our sample size (1442 observations), and that Monte-Carlo $p$-values were very similar to asymptotical ones. We consider the null hypothesis can be rejected when $p$-values are smaller than 0.10 .

Table 4 reports the test results when VaRs are computed using the Gaussian quantiles $(-1.28$ for 10 per cent, -1.64 for 5 per cent VaR, -2.33 for 1 per cent VaR), and GARCH models are normal GARCH. Results are not clearcut and depend on the VaR threshold. For a 10 per cent threshold, the worst VaR models are performed by the 250-day simple historical smoothing average (SMA250) and the GJR$\mathrm{GACH}$ models. Both (i) overestimate significantly the VaR and fail the unconditional coverage test (the ex post violation rate (VR) is significantly below 10 per cent) and (ii) fail most univariate tests $\left(L R_{C C}, E M_{C C}, L B(5)\right.$ and even $L B(10)$ tests for the former). On the other hand, the best performers are the EWMA and the $\mathrm{NARCH}$, which successfully pass every test. Other models have mixed results depending on the test statistics: the AVGARCH and the GARCH in particular exhibit $p$-values below the significance level for $L R_{C C}$.

For the 5 per cent threshold, results are similar although less clearcut. The EWMA and the NARCH models remain the best models along with the GARCH model and more surprisingly,

Table 3: Descriptive statistics for returns

\begin{tabular}{llllllll}
\hline Mean & Median & Maximum & Minimum & Std. Dev. & $\begin{array}{c}\text { Skewness } \\
(p \text {-value })\end{array}$ & $\begin{array}{c}\text { Kurtosis } \\
(p \text {-value })\end{array}$ & $\begin{array}{c}\text { Jarque-Bera } \\
(p \text {-value })\end{array}$ \\
\hline $0.0277 \%$ & $0.0270 \%$ & $2.642 \%$ & $-3.572 \%$ & $0.5789 \%$ & -0.25179 & $\begin{array}{l}5.15889 \\
(0.000)\end{array}$ & $\begin{array}{l}346.6715 \\
(0.000)\end{array}$ \\
\hline $\mathrm{Q}\left(r_{t} ; 5\right)$ & $\mathrm{Q}\left(r_{t} ; 10\right)$ & $\mathrm{Q}\left(r_{t}^{2} ; 5\right)$ & $\mathrm{Q}\left(r_{t}^{2} ; 10\right)$ & $\mathrm{ARCH}-$ & & & \\
$(p$-value $)$ & $(p$-value $)$ & $(p$-value $)$ & $(p$-value $)$ & $\mathrm{LM}(5)$ & & & \\
9.168 & 10.978 & 109.74 & 150.34 & 75.95 & & & \\
$(0.133)$ & $(0.359)$ & $(0.000)$ & $(0.000)$ & $(0.000)$ & & & \\
\hline
\end{tabular}


Table 4: Normal quantiles and normal GARCH

\begin{tabular}{|c|c|c|c|c|c|c|c|c|}
\hline & $V R(\%)$ & $\operatorname{VaR}(\%)$ & $L R_{U C}$ & $L R_{I N D}$ & $L R_{C C}$ & $E M_{C C}$ & $L B(5)$ & $L B(10)$ \\
\hline \multicolumn{9}{|c|}{ (a) Univariate tests (1-day VaR) } \\
\hline \multicolumn{9}{|l|}{$\operatorname{VaR} 10 \%$} \\
\hline SMA22 & 9.57 & 0.71 & 0.590 & 0.231 & 0.423 & 0.048 & 0.603 & 0.792 \\
\hline SMA66 & 9.15 & 0.73 & 0.282 & 0.036 & 0.062 & 0.193 & 0.200 & 0.407 \\
\hline SM250 & 7.63 & 0.75 & 0.002 & 0.022 & 0.001 & 0.010 & 0.015 & 0.010 \\
\hline EWMA & 8.88 & 0.72 & 0.150 & 0.350 & 0.230 & 0.296 & 0.807 & 0.847 \\
\hline GARCH & 8.88 & 0.73 & 0.150 & 0.039 & 0.042 & 0.171 & 0.227 & 0.170 \\
\hline EGARCH & 8.60 & 0.74 & 0.071 & 0.249 & 0.101 & 0.181 & 0.186 & 0.232 \\
\hline GJR-GARCH & 7.98 & 0.75 & 0.008 & 0.047 & 0.004 & 0.042 & 0.093 & 0.150 \\
\hline AVGARCH & 8.74 & 0.73 & 0.105 & 0.106 & 0.073 & 0.433 & 0.415 & 0.463 \\
\hline $\mathrm{NARCH}$ & 8.95 & 0.73 & 0.178 & 0.150 & 0.143 & 0.413 & 0.663 & 0.369 \\
\hline \multicolumn{9}{|l|}{$\operatorname{VaR} 5 \%$} \\
\hline SMA22 & 5.83 & 0.91 & 0.159 & 0.310 & 0.221 & 0.115 & 0.537 & 0.483 \\
\hline SMA66 & 5.13 & 0.94 & 0.814 & 0.733 & 0.918 & 0.044 & 0.299 & 0.297 \\
\hline SM250 & 5.13 & 0.96 & 0.814 & 0.042 & 0.123 & 0.388 & 0.206 & 0.168 \\
\hline EWMA & 5.55 & 0.92 & 0.345 & 0.214 & 0.296 & 0.121 & 0.418 & 0.417 \\
\hline GARCH & 5.27 & 0.94 & 0.636 & 0.299 & 0.522 & 0.461 & 0.523 & 0.555 \\
\hline EGARCH & 4.72 & 0.94 & 0.621 & 0.004 & 0.015 & 0.039 & 0.011 & 0.048 \\
\hline GJR-GARCH & 4.72 & 0.96 & 0.621 & 0.004 & 0.015 & 0.071 & 0.026 & 0.160 \\
\hline AVGARCH & 4.99 & 0.94 & 0.995 & 0.010 & 0.035 & 0.160 & 0.076 & 0.300 \\
\hline NARCH & 5.20 & 0.94 & 0.723 & 0.516 & 0.760 & 0.308 & 0.512 & 0.571 \\
\hline \multicolumn{9}{|l|}{$\operatorname{VaR} 1 \%$} \\
\hline SMA22 & 2.01 & 1.29 & 0.001 & 0.586 & 0.003 & 0.000 & 0.782 & 0.896 \\
\hline SMA66 & 1.66 & 1.32 & 0.020 & 0.357 & 0.045 & 0.005 & 0.838 & 0.910 \\
\hline SM250 & 1.46 & 1.36 & 0.102 & 0.420 & 0.190 & 0.303 & 0.716 & 0.832 \\
\hline EWMA & 1.73 & 1.31 & 0.011 & 0.338 & 0.025 & 0.011 & 0.812 & 0.901 \\
\hline GARCH & 1.25 & 1.33 & 0.360 & 0.216 & 0.307 & 0.479 & 0.597 & 0.901 \\
\hline EGARCH & 1.53 & 1.34 & 0.062 & 0.398 & 0.123 & 0.142 & 0.883 & 0.921 \\
\hline GJR-GARCH & 1.39 & 1.35 & 0.162 & 0.442 & 0.280 & 0.411 & 0.686 & 0.920 \\
\hline AVGARCH & 1.32 & 1.33 & 0.247 & 0.465 & 0.391 & 0.723 & 0.935 & 0.989 \\
\hline NARCH & 1.53 & 1.33 & 0.062 & 0.336 & 0.111 & 0.062 & 0.738 & 0.921 \\
\hline
\end{tabular}


Table 4: Continued

(b) Multivariate test

$\begin{array}{lll} & H T & P \text {-val } \\ \text { SMA22 } & 40.33 & 0.670 \\ \text { SMA36 } & 41.42 & 0.625 \\ \text { SMA250 } & 67.56 & \mathbf{0 . 0 1 6} \\ \text { EWMA } & 45.60 & 0.447 \\ \text { GARCH } & 37.90 & 0.764 \\ \text { EGARCH } & 67.45 & \mathbf{0 . 0 1 7} \\ \text { GJR-GARCH } & 44.77 & 0.482 \\ \text { AVGARCH } & 48.38 & 0.338 \\ \text { NARCH } & 31.51 & 0.936\end{array}$

Notes: $V R$ stands for the percentage of time returns prove inferior to the ex ante $\mathrm{VaR}$ forecast (ex post violation rate). $\operatorname{VaR}$ stands for the average value of the 1-day-ahead VaR forecasts. $L R_{U C}, L R_{I N D} L R_{C C}$ stand, respectively, for $p$-values of the unconditional coverage test statistic, the independence test statistic and Christoffersen's conditional coverage test statistic; $E M_{C C}$ stands for the Engle and Magnanelli's test $p$-values (5 lags). $L B(k)$ stands for the Ljung-Box's $p$-value with $k$ lags. GARCH models are estimated using a 250-day rolling window. Notes: $H T$ stands for the multivariate portmanteau's $p$-value ( $\mathrm{Li}$ and $\mathrm{Mc} \mathrm{Leod}^{16}$ ) as used by Hurlin and Tokpavi. ${ }^{15}$ We use $k=5$ lags and use three coverage rates $\alpha=1 \%, 5 \%, 10 \%$. GARCH models are estimated using a 250-day rolling window.

SMA22; the GJR-GARCH, the AV-GARCH are still among the least performing models, along with the EGARCH.

At the 1 per cent level, the ex post VR is larger than the initial coverage rate (1 per cent) for every model and reflects the leptokurtic feature of the Calyon index. The $L R_{U C}$ test, however, indicates that this difference is only significant for the SMA22, SMA66, EWMA and NARCH models. SMA22, SMA66 and EWMA also fail the $L R_{C C}$ and $E M_{C C}$ tests. SMA250, GARCH, EGARCH, AVGARCH and GJRGARCH face no rejections.

All in all, no clear distinction emerges between the models, neither between $\mathrm{GARCH}$ and simple moving average estimators, nor between symmetric or asymmetric GARCH models - when relying on the univariate statistics. Panel $4 \mathrm{~b}$ reports the HT multivariate statistic computed for three thresholds $(1,5$ and 10 per cent) and with five lags. The larger $p$ values are obtained by the NARCH and the GARCH models indicating that they are the best VaR performers throughout the thresholds. SMA250 and EGARCH both fail the test.

Turning to the VaRs computed using the Cornish-Fisher quantiles (GARCH models are still normal GARCHs), results in Table 5 turn a bit more unanimous. Quite surprisingly, with the use of these quantiles, almost every forecast method considered pass the univariate tests, including simple historical moving averages, no matter the threshold (10, 5 or 1 per cent). The only failure exceptions are the SMA250 for 10 
Table 5: Cornish-Fisher expansion quantiles with normal GARCH

\begin{tabular}{|c|c|c|c|c|c|c|c|c|}
\hline & $V R(\%)$ & $\operatorname{VaR}(\%)$ & $L R_{U C}$ & $L R_{I N D}$ & $L R_{C C}$ & $E M_{C C}$ & $L B(5)$ & $L B(10)$ \\
\hline \multicolumn{9}{|c|}{ (a) Univariate tests (1-day VaR) } \\
\hline \multicolumn{9}{|l|}{$\operatorname{VaR} 10 \%$} \\
\hline SMA22 & 11.37 & 0.64 & 0.087 & 0.326 & 0.142 & 0.015 & 0.256 & 0.178 \\
\hline SMA66 & 10.61 & 0.66 & 0.439 & 0.175 & 0.295 & 0.158 & 0.205 & 0.299 \\
\hline SM250 & 9.36 & 0.68 & 0.420 & 0.056 & 0.116 & 0.021 & 0.003 & 0.003 \\
\hline EWMA & 11.03 & 0.65 & 0.197 & 0.306 & 0.258 & 0.536 & 0.722 & 0.472 \\
\hline GARCH & 10.47 & 0.66 & 0.547 & 0.220 & 0.393 & 0.659 & 0.713 & 0.238 \\
\hline EGARCH & 10.47 & 0.66 & 0.547 & 0.141 & 0.282 & 0.510 & 0.356 & 0.435 \\
\hline GJR-GARCH & 10.12 & 0.67 & 0.868 & 0.130 & 0.313 & 0.626 & 0.422 & 0.609 \\
\hline AVGARCH & 10.47 & 0.66 & 0.547 & 0.049 & 0.120 & 0.502 & 0.368 & 0.469 \\
\hline NARCH & 10.61 & 0.66 & 0.439 & 0.175 & 0.295 & 0.582 & 0.673 & 0.257 \\
\hline \multicolumn{9}{|l|}{$\operatorname{VaR} 5 \%$} \\
\hline SMA22 & 5.55 & 0.92 & 0.345 & 0.214 & 0.296 & 0.089 & 0.358 & 0.502 \\
\hline SMA66 & 5.06 & 0.95 & 0.909 & 0.718 & 0.931 & 0.064 & 0.349 & 0.394 \\
\hline $\mathrm{SM} 250$ & 4.99 & 0.98 & 0.995 & 0.085 & 0.227 & 0.470 & 0.277 & 0.197 \\
\hline EWMA & 5.41 & 0.94 & 0.478 & 0.354 & 0.506 & 0.163 & 0.365 & 0.414 \\
\hline GARCH & 4.99 & 0.96 & 0.995 & 0.205 & 0.448 & 0.360 & 0.400 & 0.543 \\
\hline EGARCH & 4.65 & 0.96 & 0.537 & 0.013 & 0.037 & 0.102 & 0.032 & 0.106 \\
\hline GJR-GARCH & 4.65 & 0.97 & 0.537 & 0.003 & 0.011 & 0.052 & 0.019 & 0.136 \\
\hline AVGARCH & 4.85 & 0.95 & 0.803 & 0.022 & 0.070 & 0.262 & 0.132 & 0.434 \\
\hline $\mathrm{NARCH}$ & 4.99 & 0.96 & 0.995 & 0.421 & 0.724 & 0.218 & 0.461 & 0.523 \\
\hline \multicolumn{9}{|l|}{$\operatorname{VaR} 1 \%$} \\
\hline SMA22 & 0.90 & 1.65 & 0.704 & 0.614 & 0.819 & 0.981 & 0.988 & 1.000 \\
\hline SMA66 & 0.76 & 1.70 & 0.346 & 0.667 & 0.585 & 0.970 & 0.994 & 1.000 \\
\hline SM250 & 0.62 & 1.75 & 0.124 & 0.723 & 0.287 & 0.932 & 0.998 & 1.000 \\
\hline EWMA & 0.76 & 1.68 & 0.346 & 0.667 & 0.585 & 0.990 & 0.994 & 1.000 \\
\hline GARCH & 0.69 & 1.71 & 0.217 & 0.695 & 0.432 & 0.978 & 0.996 & 1.000 \\
\hline EGARCH & 0.62 & 1.72 & 0.124 & 0.723 & 0.287 & 0.942 & 0.998 & 1.000 \\
\hline GJR-GARCH & 0.55 & 1.74 & 0.064 & 0.751 & 0.171 & 0.853 & 0.999 & 1.000 \\
\hline AVGARCH & 0.69 & 1.71 & 0.217 & 0.695 & 0.432 & 0.978 & 0.996 & 1.000 \\
\hline $\mathrm{NARCH}$ & 0.69 & 1.71 & 0.217 & 0.695 & 0.432 & 0.978 & 0.996 & 1.000 \\
\hline
\end{tabular}


Table 5: Continued

(b) Multivariate test

$\begin{array}{lll} & H T & P \text {-val } \\ \text { SMA22 } & 47.66 & 0.365 \\ \text { SMA36 } & 45.37 & 0.457 \\ \text { SMA250 } & 64.15 & \mathbf{0 . 0 3 2} \\ \text { EWMA } & 47.02 & 0.390 \\ \text { GARCH } & 44.90 & 0.476 \\ \text { EGARCH } & 55.05 & 0.145 \\ \text { GJR-GARCH } & 54.67 & 0.153 \\ \text { AVGARCH } & 47.03 & 0.389 \\ \text { NARCH } & 39.97 & 0.684\end{array}$

Notes: $V R$ stands for the percentage of time returns prove inferior to the ex ante VaR forecast (ex post violation rate). $\operatorname{VaR}$ stands for the average value of the 1-day-ahead VaR forecasts. $L R_{U C}, L R_{I N D} L R_{C C}$ stand, respectively, for $p$-values of the unconditional coverage test statistic, the independence test statistic and Christoffersen's conditional coverage test statistic; $E M_{C C}$ stands for the Engle and Magnanelli's test $p$-values (5 lags). LB( $(k)$ stands for the Ljung-Box's $p$-value with $k$ lags. GARCH models are estimated using a 250-day rolling window. Notes: HT stands for the multivariate portmanteau's $p$-value ( $\mathrm{Li}$ and $\mathrm{Mc} \mathrm{Leod}^{16}$ ) as used by Hurlin and Tokpavi. ${ }^{15}$ We use $k=5$ lags and use three coverage rates $\alpha=1 \%, 5 \%, 10 \%$. GARCH models are estimated using a 250-day rolling window.

per cent VaR estimates, the EGARCH and GJR-GARCH models for the 5 per cent VaR estimates, which all exhibit significant violation clustering (cf panel 3a). Note that contrary to the pure Gaussian case in Table 2, the ex post $\mathrm{VR}$ are much closer to the ex coverage rate for the 10 and 5 per cent thresholds with only one rejection for $L R_{U C}$. These results are largely confirmed by the multivariate HT statistic reported in panel $3 \mathrm{~b}$ with only one rejection for the SMA250; the NARCH model has the highest $p$-value.

Table 6 reports the results for the VaR estimates using the Student quantiles with eight degrees of freedom. GARCH volatility forecasts are also taken from $t$-GARCH estimates. Panel 4a shows that for large VaR thresholds (10 or 5 per cent), no variance forecasting model is optimal. Interestingly, every model fails $L R_{C C}$ and $E M_{C C}$ tests at these thresholds. For the former test, most of failures stem from the failure of the unconditional coverage tests: using Student quantiles induce a substantial overestimation of the VaR of the CTA index for 10 and 5 per cent thresholds, whatever the models used to make volatility forecasts (the results are unchanged using seven degrees of freedom instead of eight). With a more stringent threshold of 1 per cent, the results get much better since every model then pass the univariate tests successfully. Interestingly, at this threshold level, $p$-values are almost systematically larger than those obtained in Tables 4 and 5 by the Gaussian and Cornish-Fisher methods, showing 
Table 6: Student quantiles and t-GARCH

\begin{tabular}{|c|c|c|c|c|c|c|c|c|}
\hline & $V R(\%)$ & $\operatorname{VaR}(\%)$ & $L R_{U C}$ & $L R_{I N D}$ & $L R_{C C}$ & $E M_{C C}$ & $L B(5)$ & $L B(10)$ \\
\hline \multicolumn{9}{|c|}{ (a) Univariate tests (1-day VaR) } \\
\hline \multicolumn{9}{|l|}{$\operatorname{VaR} 10 \%$} \\
\hline SMA22 & 7.98 & 0.77 & 0.008 & 0.451 & 0.023 & 0.038 & 0.587 & 0.908 \\
\hline SMA66 & 7.63 & 0.80 & 0.002 & 0.097 & 0.002 & 0.009 & 0.066 & 0.098 \\
\hline SM250 & 6.80 & 0.82 & 0.000 & 0.040 & 0.000 & 0.003 & 0.117 & 0.205 \\
\hline EWMA & 7.63 & 0.78 & 0.002 & 0.649 & 0.007 & 0.048 & 0.829 & 0.821 \\
\hline GARCH & 7.07 & 0.80 & 0.000 & 0.070 & 0.000 & 0.009 & 0.254 & 0.264 \\
\hline EGARCH & 7.00 & 0.80 & 0.000 & 0.061 & 0.000 & 0.002 & 0.080 & 0.126 \\
\hline GJR-GARCH & 6.80 & 0.81 & 0.000 & 0.016 & 0.000 & 0.000 & 0.002 & 0.004 \\
\hline AVGARCH & 7.56 & 0.80 & 0.001 & 0.285 & 0.003 & 0.021 & 0.136 & 0.221 \\
\hline NARCH & 7.42 & 0.80 & 0.001 & 0.030 & 0.000 & 0.014 & 0.175 & 0.244 \\
\hline \multicolumn{9}{|l|}{$\operatorname{VaR} 5 \%$} \\
\hline SMA22 & 4.30 & 1.03 & 0.214 & 0.060 & 0.079 & 0.026 & 0.104 & 0.303 \\
\hline SMA66 & 3.74 & 1.06 & 0.023 & 0.470 & 0.057 & 0.010 & 0.189 & 0.115 \\
\hline SM250 & 2.84 & 1.09 & 0.000 & 0.117 & 0.000 & 0.007 & 0.348 & 0.732 \\
\hline EWMA & 3.68 & 1.04 & 0.016 & 0.437 & 0.040 & 0.098 & 0.664 & 0.411 \\
\hline GARCH & 3.40 & 1.06 & 0.003 & 0.712 & 0.012 & 0.111 & 0.806 & 0.901 \\
\hline EGARCH & 2.98 & 1.07 & 0.000 & 0.009 & 0.000 & 0.001 & 0.013 & 0.081 \\
\hline GJR-GARCH & 3.12 & 1.08 & 0.000 & 0.059 & 0.000 & 0.021 & 0.200 & 0.622 \\
\hline AVGARCH & 3.05 & 1.06 & 0.000 & 0.011 & 0.000 & 0.002 & 0.014 & 0.057 \\
\hline NARCH & 3.47 & 1.06 & 0.005 & 0.345 & 0.012 & 0.068 & 0.476 & 0.707 \\
\hline \multicolumn{9}{|l|}{$\operatorname{VaR} 1 \%$} \\
\hline SMA22 & 0.97 & 1.60 & 0.913 & 0.587 & 0.858 & 0.990 & 0.983 & 0.999 \\
\hline SMA66 & 0.83 & 1.65 & 0.511 & 0.640 & 0.722 & 0.950 & 0.992 & 1.000 \\
\hline SM250 & 0.69 & 1.69 & 0.217 & 0.695 & 0.432 & 0.975 & 0.996 & 1.000 \\
\hline EWMA & 0.83 & 1.63 & 0.511 & 0.640 & 0.722 & 0.992 & 0.992 & 1.000 \\
\hline GARCH & 0.76 & 1.66 & 0.346 & 0.667 & 0.585 & 0.988 & 0.994 & 1.000 \\
\hline EGARCH & 0.76 & 1.66 & 0.346 & 0.667 & 0.585 & 0.984 & 0.994 & 1.000 \\
\hline GJR-GARCH & 0.62 & 1.69 & 0.124 & 0.723 & 0.287 & 0.915 & 0.998 & 1.000 \\
\hline AVGARCH & 0.69 & 1.65 & 0.217 & 0.695 & 0.432 & 0.978 & 0.996 & 1.000 \\
\hline NARCH & 0.69 & 1.66 & 0.217 & 0.695 & 0.432 & 0.978 & 0.996 & 1.000 \\
\hline
\end{tabular}


Table 6: Continued

(b) Multivariate test

$\begin{array}{lll} & H T & P \text {-val } \\ \text { SMA22 } & 38.63 & 0.737 \\ \text { SMA36 } & 49.55 & 0.297 \\ \text { SMA250 } & 48.08 & 0.349 \\ \text { EWMA } & 37.22 & 0.789 \\ \text { GARCH } & 43.70 & 0.527 \\ \text { EGARCH } & 58.45 & \mathbf{0 . 0 8 6} \\ \text { GJR-GARCH } & 71.10 & \mathbf{0 . 0 0 8} \\ \text { AVGARCH } & 72.24 & \mathbf{0 . 0 0 6} \\ \text { NARCH } & 42.24 & 0.590\end{array}$

Notes: $V R$ stands for the percentage of time returns prove inferior to the ex ante VaR forecast (ex post violation rate). $\operatorname{VaR}$ stands for the average value of the 1-day-ahead VaR forecasts. $L R_{U C}, L R_{I N D} L R_{C C}$ stand, respectively, for $p$-values of the unconditional coverage test statistic, the independence test statistic and Christoffersen's conditional coverage test statistic; $E M_{C C}$ stands for the Engle and Magnanelli's test $p$-values (5 lags). LB( $(k)$ stands for the Ljung-Box's $p$-value with $k$ lags. GARCH models are estimated using a 250-day rolling window. Notes: HT stands for the multivariate portmanteau's $p$-value ( $\mathrm{Li}$ and $\mathrm{Mc} \mathrm{Leod}^{16}$ ) as used by Hurlin and Tokpavi. ${ }^{15}$ We use $k=5$ lags and use three coverage rates $\alpha=1 \%, 5 \%, 10 \%$. GARCH models are estimated using a 250-day rolling window.

logically that Student quantiles are better to forecast extreme losses. The HT statistics in panel $4 \mathrm{~b}$ indicate three rejections for the EGARCH, GJR-GARCH and N-GARCH models.

To conclude, our results first show that for the Barclay/Calyon CTA index, efficient VaR forecasts depends much more on the quantile used for computing VaR, than on the choice of the model used to forecast volatility (simple smoothing average, EWMA, symmetric or asymmetric GARCH models). Second, and in line with Monteiro, ${ }^{10}$ the Cornish-Fisher quantiles appear the easiest and the most flexible way to obtain efficient VaR forecasts: even combined with very simple volatility estimators, $\mathrm{VaR}$ forecasts manage to respect the unconditional coverage and violation independence conditions at least for 10 and 5 per cent thresholds.

\section{CONCLUSION}

As NAV were formerly exclusively available on a monthly basis, there is a growing pressure for hedge funds to issue weekly or even daily NAV estimates, so as to improve transparency as well as risk management capacity. The main contribution of this paper is to conduct an empirical investigation of hedge fund $\mathrm{VaR}$ using daily returns of an hedge fund index, namely the Barclay CTA index, which starts as early as January 2000.

For various thresholds, we consider several methods to compute 1-day-ahead VaR forecasts 
using different types of quantiles (Gaussian, Cornish-Fisher expansion, Student) and volatility forecasting models (historical averages, EWMA, GARCH and t-GARCH). We compare these estimates, using univariate and multivariate back-testing procedures aimed at checking their efficiency both in terms of unconditional coverage and independence of $\mathrm{VaR}$ violations.

Our results show that for the Barclay/Calyon CTA index, the efficiency of $\mathrm{VaR}$ forecasts primarily depends on the type of quantiles used for computing VaR. The choice of the model used to forecast volatility (simple smoothing average, EWMA and symmetric or asymmetric GARCH models) proves much less important in that specific case. Our results also show that the most flexible form is the Cornish-Fisher expansion, since it enables even very simple volatility models to pass successfully back-testing tests for 10, 5 or even 1 per cent VaR thresholds. Thus, our results seem in line with those of Monteiro ${ }^{10}$ on monthly data. On the other hand, Student VaRs are the best to compute 1 per cent VaR forecasts, although they are illadapted for larger thresholds (with large VaR overestimations). All in all, if on the one hand, our results need confirmation before being generalised, they are, on the other hand, somewhat reassuring for risk managers as they show that making good VaR estimations for hedge funds seems achievable.

\section{Acknowledgments}

We would like to thank Habib Hjiej and Sebastien Lebkiri for excellent research assistance.

\section{References}

1 Lhabitant, F. -S. (2001) 'Assessing Market Risk for Hedge Funds and Hedge Fund Portfolios', Journal of Risk Finance, Summer, pp. 16-32.
2 Sharpe, W. F. (1988) 'Determining a Fund's Effective Asset Mix', Investment Management Review, Vol. 2, No. 6, pp. 59-69.

3 Sharpe, W. F. (1992) 'Asset Allocation: Management Style and Performance Measurement', Journal of Portfolio Management, Vol. 18, No. 2, 7-19.

4 Pochon, F. and Teiletche, J. (2006) 'A Conditional Approach to Hedge Fund Risk', The Journal of Alternative Investment, Vol. 9(Summer), pp. 64-77.

5 Pochon, F. and Teiletche, J. (2006) 'The Market Risk of Funds of Hedge Funds: A Conditional Approachin Gregoriou, G.N. (ed.), 'Funds of Hedge Funds: Performance, Assessment, Diversification and Statistical Properties', Elsevier, Cambridge.

6 Signer, A. and Favre, L. (2002) 'The Difficulties of Measuring the Benefits of Hedge Funds', The Journal of Alternative Investments, Vol. 5, pp. 31-42.

7 Zangari, P. (1996) 'An Improved Methodology for Measuring VaR', RiskMetrics Monitor, Second quarter, pp. 7-25.

8 Bacmann, J. -F. and Gawron, G. (2004) 'Fat Tail Risk in Portfolios Of Hedge Funds and Traditional InvestmentsWorking Paper, RMF Investment Management.

9 Bali, T. G. and Gokcan, S. (2004) 'Alternative Approaches to Estimating VaR for Hedge Fund Indicesin Schachter, B. (ed.), 'Intelligent Hedge Fund Investing', RiskBook, London.

10 Monteiro, P. (2004) 'Forecasting Hedge Funds Volatility: A Risk Management Approach, Working Paper, Banco Alves Riberio Working Paper. Available on http://www.gloriamundi.org/.

11 Christoffersen, P. F. (1998) 'Evaluating Interval Forecasts', International Economic Review, Vol. 39, pp. 841-862.

12 Campbell, S. D. (2005) 'A Review of Backtesting and Backtesting ProceduresBoard of Governors of the Federal Reserve, Finance and Economics Discussion Series no 2005-21.

13 Berkowitz, J., Christoffersen, P. F. and Pelletier, D. (2005) 'Evaluating Value-at-Risk Models with Desk-Level DataWorking Paper, Mc Gill University.

14 Engle, R. F. and Manganelli, S. (2004) 'CAViaR: Conditional Autoregressive Value-at-Risk by Regression Quantiles', Journal of Business and Economic Statistics, Vol. 22, pp. 367-381.

15 Hurlin, C. and Tokpavi, S. (2006) 'Backtesting VaR Accuracy: A New Simple Test Working Paper, University of Orléans.

16 Li, W. K. and McLeod, A. I. (1981) 'Distribution of the Residual Auto-correlations in Multivariate ARMA Time Series Models', Journal of the 
Royal Statistical Society, serie B, Vol. 43, pp. 231-239.

17 Canina, L. and Figlewski, S. (1993) 'The Informational Content of Implied Volatility', Review of Financial Studies, Vol. 6, pp. 659-681.

18 Jorion, P. (1995) 'Predicting Volatility in the Foreign Exchange Market', Journal of Finance, Vol. 50, No. 2, pp. 507-528.
19 Hansen, B. E. (1994) 'Autoregressive Conditional Density Estimation', International Economic Review, Vol. 35, No. 3, pp. 705-730.

20 Dufour, J. M. (2004) 'Monte Carlo Tests with Nuisance Parameters: A General approach to Finite-Sample Inference and Nonstandard AsymptoticsDiscussion Paper, CIRANO and CIREQ, Université de Montréal. 